\title{
A Book Review of Tourism, Poverty and Development by Andrew Holden
}

\author{
Geoffrey K. Riungu \\ Department of Parks, Recreation and Tourism Management, Clemson University, USA \\ Email: gkoome@yahoo.com
}

Received 19 March 2015; accepted 3 April 2015; published 8 April 2015

Copyright (C) 2015 by author and OALib.

This work is licensed under the Creative Commons Attribution International License (CC BY). http://creativecommons.org/licenses/by/4.0/

(c) O) Open Access

\begin{abstract}
Andrew Holden's book titled "Tourism, Poverty and Development" [1] gives a solid introduction of how a pro poor tourism agenda can be used to alleviate poverty and propel development in Least Developing Countries (LDCs). The book uses case studies to paint a picture of the prevailing conditions in LDCs and how some countries are trying to use tourism as a stepping stone towards freeing themselves from economic and social bondage. The book also brings into question the motivation behind Bretton wood institutions and their halfhearted attempts to alleviate poverty in developing economies. Some of the drawbacks in this book include the lack of a holistic view of the African continent that primarily has a majority of LDCs especially with the lack of attention to North African countries and the status of poverty there.
\end{abstract}

\section{Keywords}

Poverty, Developing Countries, Tourism Development, Pro Poor Tourism

Subject Areas: Literature, Sociology

The book used relevant case studies to provide a simplified yet descriptive introduction of poverty and how it can be alleviated through tourism development in the Least Developing Countries (LDCs). Pro poor tourism is advocated as an avenue for poverty reduction since it enables the poor to actively participate in and significantly benefit from tourism related economic activity. Andrew Holden provides a holistic description of poverty, from an economical, spiritual and nutritional context. Further, absolute poverty and relative poverty are identified as types of poverty. The book defines absolute poverty as a condition in which physiological, educational and democratic needs and rights fail to be met [2]. Subsequently, when a time dimension is added, then it becomes chronic poverty likely to persist for a long time. Conversely, relative poverty is culturally defined as being poor against the living standards of society.

The book indicates the apparent lack of one suitable measure that can be used to reveal the quality of people's 
lives. Therefore it dismisses the use of income as the sole determinant of the quality of life and calls for the integration of social discrimination, physical insecurity, political exclusion and empowerment into the description of poverty. This is replaced by the US\$1.25 per capita per day (from the previous US\$1) minimum income level used by the World Bank and United Nations as a simple indicator of poverty.

The author identifies colonialization, capitalism, poor governance, lack of infrastructure, population growth and resource pressures, and conflict as posing significant challenges to poverty reduction. The geography of a country is also likened to affect economic development, for instance, landlocked countries may have no access for trade, low levels of education and skill, and a lack of available fossil fuels. Additionally, a link between the Bretton wood institutions and the slow development of LDCs is explained. The policies placed upon such countries when accessing funds appear to be pegged on the agenda of these institutions instead of being owned by the individual countries. Additionally, the interest rates charged are retrogressive to these countries' development projects. The lack of adequate representation from developing countries in the World Trade Organization, World Bank and International Monetary Fund further escalates this issue. China is identified in the book as an alternative source of funding. However, the book falls short in providing a comprehensive description on whether this "alternative" is making tangible progress on the development agenda of the LDCs.

Holden attempts to draw out a convergence between poverty reduction and tourism. The emergence of railroad is identified as a precursor to tourism activities since it has brought about interconnection between places. ICT and the internet are recent development in the globalization push. Conversely, tourism is identified as an alternative industry from the main stream manufacturing/production or agricultural sectors. This is mainly because the LDCs possess natural assets as well as cultural values that tend to pull tourists to these areas. With global tourism being the leading revenue generating industry, LDCs are bound to gain if they tap into this industry. Kenya for instance, has incorporated tourism as a major economic pillar in its Vision 2030 Strategic Plan. This is meant to ultimately reduce poverty in Kenya which is in line with the United Nation Millennium Development Goals.

Further, Holden reiterates that economic growth should be oriented towards the poor rather than assuming they will eventually be beneficiaries of economic growth. Therefore the tourism trickledown theory is dismissed in this book in favor of poverty being the main agenda in poverty reduction strategies. Pro poor tourism (PPT) is then proposed with a view to enhance linkages between tourism businesses and poor people so that tourism contribution to poverty reduction is increased. For example, through the establishment of community based projects like the Annapurna Conservation Area in Nepal. Further, the book provides an avenue for debate as to whether the exploitation of poverty as a tourism product/activity, like the case of slum tourism in Kenya. This is likely to elicit diverse opinions among tourism scholars and students on the economic, cultural and social impacts such practice may have.

In trying to carve out a relationship between tourism and poverty reduction, the book ignores other platforms like manufacturing and technology that were key to emerging economies like China, India and Brazil. This was magnified by the lack of an illustration of a country (if any) that has developed primarily due to a vibrant tourism industry. However, in fairness the author does warn that tourism will not be a quick fix for poverty reduction. This is because it is reliant on other factors like good governance which would address the lack of welldesigned policies for sustainable development and cultures of peace. Infrastructure development is also fundamental in the prosperity of the tourism trade.

Another drawback is that the book did not mention North African countries and whether these countries are developed or not, and the status of poverty and tourism in these countries. This is a vital link that can give the reader an opportunity to evaluate Africa as a whole and possibly identify best practices that may be adapted from different regions.

Overall the text provides a comprehensive introduction on poverty and tourism development in LDCs and opens up room for further interrogation like how politicians especially in Africa may induce poverty so as to remain in power. This is because their subjects are not empowered and they use this to stay in their "empires". Furthermore, discussions can be raised on the accessibility to capital for the poor to start tourism related enterprises in LDCs.

\section{References}

[1] A. Holden (2013) Tourism, Poverty and Development. Routledge, New York.

[2] Chronic Poverty Research Centre (CPRC) (2009) The Chronic Poverty Report 2008-9: Escaping Poverty Traps. CPRC, Manchester. 